\title{
Support Provided by Public Health Nurses for Fathers Who Have Abused Their Children-As Observed in Cases of Child Neglect and Physical or Psychological Abuse
}

\author{
Izumi Ueda \\ Department of Nursing School of Health Sciences, Sapporo Medical University, Sapporo, Japan \\ Email: iueda@sapmed.ac.jp
}

Received 20 January 2016; accepted 22 February 2016; published 25 February 2016

Copyright (C) 2016 by author and Scientific Research Publishing Inc.

This work is licensed under the Creative Commons Attribution International License (CC BY). http://creativecommons.org/licenses/by/4.0/

(c) (i) Open Access

\section{Abstract}

This study aims to identify the support to provide to fathers who have abused children as reported by public health nurses (PHNs). In this study, a qualitative descriptive design was applied to the data analysis. Interviewees were 10 public health nurses (PHNs) in charge of child abuse services for at least 5 years at public health centers. The study analyzed 13 cases reported in the interviews. Measures to support fathers who abuse their children as suggested by PHNs were classified into direct support to the father, support to other family members, and support to be provided by others involved including related organizations. The direct support to the father includes "gaining an in-depth understanding of the abusive situation and psychological states of those involved", "refraining from involvement in areas where it is difficult to understand the personality of the father", and others. Support of other family members includes "understanding the marital relationship and assessing the qualities of the relationship", "refraining from matters that will involve divorce", and others. Support to be provided by others including related organizations includes "understanding the value of social exchange and assessment of the ability to create and maintain interpersonal relationships", "establishing support arrangements to enable intervention when necessary", and others. The interviews report that PHNs arrange support measures that enable intervention as it becomes required, and that this enables learning about child-abuse preventing activities.

\section{Keywords}

Public Health Nurse, Child Abuse, Father, Support Contents 


\section{Introduction}

The Japan report on "Verification of causes of deaths from child abuse" outlines details of deaths from all child abuse cases. The incidence of deaths of children below one year of age due to child abuse is the highest among abuse cases, and the total for children up to five years of age is about $90 \%$ [1]. This shows early infancy as an especially critical time for supportive intervention in child abuse cases. The PHNs at public health departments and health centers provide maternal and child health services for infants and women in childbirth based on the Maternal and Child Health Law of Japan [2].

Many studies conducted outside Japan have focused on fathers to establish risk factors contributing to child abuse, including studies of fathers displaying a high incidence of being the source of physical abuse and neglect, general risk assessments, and the roles of fathers in abuse and neglect cases [3] [4]. From Japan, there are reports comparing the characteristics of biological mothers and fathers, as well as there are reports of intervention with groups of fathers in Tokyo [5] [6], and this field has recently attracted research attention. However, there are few studies that focus on the characteristics of fathers. A reason why the research in Japan differs from that of other countries may be due to differences in societal perceptions, including differences in the periods of the studies researchers have focused on child abuse as a social issue and in behaviors pertaining to child abuse.

The results of the review of the literature on the characteristics of fathers in cases with child abuse and neglect clearly show that the characteristics of fathers in child abuse case involve negative feelings and attitudes towards the family [7]. There is a preliminary study with the objective to describe how public health nurses (PHNs) understand the characteristics of the interpersonal relations and behaviors of fathers who cause child abuse [8].

The present study conducted interviews with experienced PHNs who had been involved in child abuse cases while providing maternal and child health services, and investigated opinions (understanding) of the kinds of support provided for fathers.

\section{Methods}

\subsection{Operational Definitions of Terminology}

\section{1) Child abuse}

There are different definitions of child abuse. The Child Abuse Prevention Law of Japan defines physical abuse such as striking, kicking, and sexual abuse, as well as psychological abuse and neglect under the umbrella term "child abuse". In the study here "child abuse" is defined as physical abuse, psychological abuse, and neglect as stipulated in The Child Abuse Prevention Law. Some studies have reported that the pathology of sexual abuse originates in factors of the perpetrator, such as the desire for emotional contact, sexual stimulation, and for other reasons [9]. Sexual abuse was excluded from the study here because the pathology of sexual abuse may be seen to differ from that of the other types of child abuse.

\section{2) Father}

"Father" here refers to either a biological father or to a person viewed as the father to the children, the male who plays the role of father to a child.

\subsection{Design and Sample}

The study applied a qualitative descriptive design to the data analysis. In a prefecture the study identified a region where social resources such as medical welfare services for children are well established, and made a request for cooperation from health care centers where permission to approach the personnel had been obtained. At these health care centers, we recruited participants (interviewees) from among experienced PHNs, personnel in charge of maternal and child health services at the time of the study and with at least five years experience in dealing with child abuse cases. The types of abuse that the participating PHNs would be interviewed about were limited to physical abuse, mental abuse, neglect, or a combination of these, but no specific identification of the family member instigating the abuse in the family was indicated.

Interviewees were 10 public health nurses (PHNs). The interviewees were asked to recall one or two fathers they had assisted in their capacity as a PHN and tell about the case. The study analyzes 13 cases reported in the PHNs interviews. 


\subsection{Interview Methods}

Data were collected with semi-structured interviews based on interview guidelines between July and August 2011. The interviewer of this study was author. Upon obtaining consent (details in the Ethical Considerations section below), the narratives were recorded using an integrated circuit recorder, and the interviews lasted an average of 56 minutes (range 45 - 86). The interviewees were requested to recall a father they had assisted in their capacity as PHNs and tell about the case. All the interviewees talked about the cases referencing the case records which were available at the interview. Firstly, the participants were asked to outline the causes of the case, including details of the family structure. The main questions in the interviews were the kind of support to give the fathers. The kind of support contents were classified into direct support to the father, support to family members, and support provided by others involved including related organizations. The participants were asked to detail in these support. The interview was conducted in the work place of the interviewee in a location where privacy could be ensured.

\subsection{Data Analysis}

The data obtained by recording and transcribing the narratives were analyzed by employing a qualitative descriptive design, and classified by the relevance of a sentence or of expressions/topics that appeared to suggest a matter of importance. Examining the contexts which showed characteristics of the fathers and assigning a code marker which would not hide the meaning, a list with the codes for these items was created for each interview. With the cases to be analyzed, organizing by the codes for similar matters, and reviewing the concepts represented by these, the data were classified into subcategories. Then, identifying similarities in the subcategories and examining the items, each subcategory was assigned a name to be abstracted. In this process the level of abstraction was carefully monitored with a final assignation to a category, from subcategories, code, and data. The validity of the categories was assured by repeated coding and discussion among the participating researchers. For verification of the results, the interviewees were asked to check for variance with the facts or for other problems they felt that there were in the extracted categories and subcategories and whether the categories reflected the matters those interviewees had told.

\subsection{Ethical Considerations}

This study was carried out after obtaining informed consent from the participating centers by providing an outline of the study to the director of the participating health care center orally and through a letter requesting cooperation in the study. The outline of the study was also explained to the participating PHNs (interviewees) orally and through the letter to request participation in the study, and written consent was obtained. All participants were assured that confidentiality would be maintained at all times, research findings would not be used for purposes other than the study here, and that the cases would be carefully handled as would the anonymity of both PHNs and others involved in the cases. We obtained approval to conduct the study from the Ethics Committee of Sapporo Medical University.

\section{Results}

\subsection{Research Participants and Outline of the Cases}

A total of thirteen cases were brought up by the interviewees. All cases were caused by neglect by the parents, and involved abuse of a physical or psychological nature. All the interviewees working at the health care centers were female with an average of 8 years and 6 months (range 6 - 13 years) of experience in dealing with child abuse cases.

\subsection{The Kinds of Support for the Fathers Who Had Abused Their Children}

The analysis yielded 18 categories and 35 subcategories, for a total of 57 code designations.

The 18 categories were classified into direct support for the father, support for other family members, and support provided by others involved including related organizations. The categories are expressed with single quotation marks (" ") in the following, and the parts quoting interview data are expressed by the interviewees, the PHNs. 


\subsection{Direct Support to the Father}

1) "gaining an in-depth understanding of the abusive situation and psychological states of those involved"

When fathers hit/slap their children with their hands, they may think it natural to do so to discipline their children because their own parents raised them in the same way.

2) "considering the history of the development as displayed by the father"

The father may be a person who feels it is difficult to get through life. He may have problems like with getting angry easily, and have difficulty in communicating what he wants to say. His parents may have raised him strictly because it was difficult to deal with him as a child.

3) "identifying the intentions and psychological state of the father that contributes to the abuse"

When the father pushes his child away with excess force if child comes too near when he (the father) is playing a TV game, he gives priority in what he wants to do. He is not angry at his child but the child senses the father thinks the child troublesome.

4) "refraining from involvement in areas where it is difficult to understand the personality of the father"

Even if we get new information about the fathers from other sources (authorities), we do not disclose what we know about the domestic violence because we did not hear this ourselves. This makes it difficult to respond to some situations and assess the need for intervention.

5) "confirming the state of child development and assessing the environment where the child is brought up and ability of the family"

I think the best opportunity for us to know about fathers is at a physical check-up for infants. Parents bring their children to the check-up when the youngest child is 18 months old. We have to confirm that fathers will have their children come in for the check-up, and then we are able to check the development of the children.

6) "thinking about the development of the child within the framework of the family and providing instructions for the father to assist in furthering the development of the child"

We follow up the development of children while contacting medical institutions to share information. We assist in the development of the children by confirming the development and family circumstances.

7) "understanding the life experience and assisting the financial ability to support the family"

The father obtains just any sort of employment, but changes jobs irregularly. We have to determine whether the father can be expected to continue working to ensure the livelihood of the family.

8) "assisting the family in making improvements in the life style"

The father is out of work and on welfare, and has no plans to seek employment. Further, he uses the help services of welfare programs. We make arrangements for him to become enrolled in existing services.

\subsection{Support to Family Members}

1) "understanding the marital relationship and assessing the qualities of the relationship"

The husband and wife insist on their own different opinions. If it appears that the wife speaks up too readily, there may remain some room to improve the marital relationship. We evaluate what it is possible to do by listening to them both and trying to understand hidden messages.

2) "telling the father about a father's role in supporting the mother and attempt to stabilize the marital relationship"

We assist the family by suggesting what the father can do to support the mother's mental condition and to share in the child care.

3) "refraining from matters that would involve divorce"

While listening to the family, I thought it was a problem between the husband and wife, and I drew back from making suggestions. I told them they have to settle the problem of a possible divorce, and that a public health nurse cannot be involved in that kind of matters.

4) "understanding who the main person in the family is and how this person supports the family, and also assessing the child-rearing environment of the family"

There is no one to hold the family together. If the father falls ill, the family will be unable to secure a livelihood. Here we assess the child-rearing environment of the family while paying attention to the health condition of the father.

5) "encouraging acceptance of support advice in the bringing up the children and informing of the kinds of support the family can receive" 
When the father's health is good, we tell him the good points in his child care, and praise him.

\subsection{Support Provided by Others Involved Including Related Organizations}

1) "understanding the value of social exchange and assessment of the ability to create and maintain interpersonal relationships"

We have never heard any friends. Both the father and mother have a very small social network. But we still know they are not socially isolated because they associate with limited number of friends.

2) "creating links with involved parties and telling the kind of roles they may play"

They are rarely involved with their neighbors and parents. This is why authorities concerned have to support the family. First of all we try to create a relationship where the family can tell about their problems to public health nurses.

3) "establishing support arrangements to enable intervention when necessary"

I think he will reject any intervention regardless of which authority intervenes. Then we have to just wait, and watch for an opportunity like when the father is working. The father does not seek for our help. I will then make the necessary arrangements with the authority concerned. I prepare to introduce interventions immediately when they are needed.

4) "alerting relevant organization to be in contact with the family to detect signs of abuse earliest possible"

We felt relieved to know that the children started to go to nursery school. The authority concerned has been keeping a close eye on whether there are signs of child abuse.

5) "sharing information and establishing support frameworks to provide interventions as required"

We contacted the child consultation center. So, we think a child welfare worker will provide intervention. Public health nurses will provide and share information during a care meeting.

\section{Discussion}

The kinds of support in this study are classified into direct support for the father, support for other family members, and support provided by others involved including related organizations. Kahn \& Antonucci have proposed a convoy model related social network [10].

This model represents the structure of a network centered on fathers. The results in the present case are also similar: the public health nurse (hereinafter, PHN) has structurally conceptualized the social circles comprising close family members and other acquaintances of the father.

In supporting the father, the PHN has a strong awareness of the contexts of abuse and situations that gave rise to such abuse, as well as a detailed understanding of the father's psychological state while abusing his children. It seems that the father support begins with the PHN trying to understand the father's image.

The PHN tries to understand not only the psychological state of the father but also the environment in which he is raised. In understanding the background of the father's abusive psychology, it is important to know how the father expresses his emotions; therefore, the psychological state of the father must be understood in a comprehensive manner [6].

In this case, it is revealed that it is difficult to assess the details of the father's image, which results in not being able to evaluate the intervention. As the International Labor Organization has reported recently, medical professionals are likely to be subjected to violence in their work environment. Violence in the medical environment is a very serious social problem [11]. Violence in an at-home care setting also has to be examined. It is essential to find new methods to approach cases such as how to handle the situation when the PHN experiences fear when visiting the father alone at his home.

As indicated in previous studies on support for mothers [12], thinking about children's growth and development with their parents and providing parents with concrete advice on how to interact with their children are equally essential roles of PHNs, irrespective of the parent being a mother or a father.

The PHN ascertains whether the relationship between the husband and wife is stable, and provides support to maintain the spousal relationship. In order to encourage the father to adjust to his role as a father, preparation for the role, education, as well as spousal communication is necessary [13]. It is essential to provide learning opportunities for the father to be educated on his role and to support so that the father can build a stable family relationship.

The PHN determines the key person(s) in the family and considers solutions for child-rearing issues with the 
family. In recent years, social environment surrounding child rearing in Japan has changed significantly, e.g., the trend of nuclear families and changes in local communities [14]. It has been indicated that the family alone often cannot bear all the responsibilities of raising children, which leads to abuse. It is necessary to activate the cooperation and network in the local community, such as relatives and neighbors [15]. All the cases in the current study are nuclear families. The PHN assesses the support status and provides support to improve the child-rearing ability of the whole family. It seems that the PHN is empowering the father and the family members.

The PHN ascertained father's the relationships people who surrounded him to verify whether he was socially isolated or not. Furthermore, the PHN helped the father build relationships with those who are involved, and provided him with the roles others play. When the family is isolated from the surroundings, it delays the child abuse from being noticed, which leads to serious risk. By constantly understanding the father's relationship with non-family members, the PHN seemed to be trying to determine whether the father had the ability to form relationships with non-family members. In this case, the PHN mediated the father to start forming relationships with people that the father could build a trusting relationship, when the father exhibited rejective tendency to people surrounding him. It is important to create a space where the father can express himself with a sense of security and build relationships [16].

In Japan, network collaboration of related agencies has been legislated to prevent child abuse [17]. Health authorities are anticipating collaboration between child consultation centers and network construction. The result of building the support system as seen in this case is in concert with the government measures. It was found that PHNs arrange support measures that enable intervention as it becomes required, and that this enables learning of suggestions for child-abuse preventing activities. Also, the findings show the difficulties of intervention where it is difficult to understand a father's personality when identifying the existence of an abusive situation. This emphasizes the necessity to understand a father's mental state to be able to establish a supportive relationship with the father. It became clear that the support provided for fathers in collaboration with related organizations includes efforts to obtain knowledge of the fathers and share information as well as establish a support framework for implementation of the support. It was found that PHNs arrange support measures that enable intervention as it becomes required, and that this enables learning of suggestions for child-abuse preventing activities. Also, the findings show the difficulties of intervention where it is difficult to understand a father's personality when identifying the existence of an abusive situation. This emphasizes the necessity to understand a father's mental state to be able to establish a supportive relationship with the father.

\section{Acknowledgements}

The research team expresses thanks to the participants for accepting to be interviewed and making room in their busy schedules.

\section{Limitations}

The present study has the following limitations: we addressed only cases that were dealt with by PHNs who worked in public health centers. The support contents of the fathers were not reported by the fathers themselves or others involved, but the support contents perceived by the PHNs.

\section{References}

[1] Committee on Council of Social Security of Children Section Concerning Child Abuse (2013) The 9's Analysis Reports by Death Cases of Child Abuse and Neglect: Ministry of Health, Labor and Welfare. http://www.mhlw.go.jp/stf/houdou/2r98520000037b58-att/2r98520000037bag.pdf

[2] Izumi, U. and Kazuko, S. (2009) 6-1 Public Health Nurse’s Care for Mother and Child health. New Child Care for Neighborhood Action. Chuuouhoukisyuppan Press, Tokyo, 224-231.

[3] Coohey, C. (2006) Physically Abusive Fathers and Risk Assessment. Child Abuse \& Neglect, 30, 467-480. http://dx.doi.org/10.1016/j.chiabu.2004.10.016

[4] Dubowitz, H., Black, M.M., Kerr, M.A., et al. (2000) Fathers and Child Neglect. Arch Pediatric Adolescent Medicine, 154, 135-141. http://dx.doi.org/10.1001/archpedi.154.2.135

[5] Hokenhukusikyoku, T. (2007) Zidougyakutainozittai2-Kagayakaseyoukodomonomirai. www.mhlw.go.jp/bunya/kodomo/dv36/index.html

[6] Takeshi, T. (2007) Psychoeducational Approaches for Families: Concept and Methods: Approaches for Fathers Group. 
Kanekosyobou Press, Tokyo, 59-73.

[7] Izumi, U., Kazuko, S., Mariko, K., et al. (2010) Reviews of Domestic and International Research Papers on the Characteristics of Fathers Regarding Child Abuse. Japanese Journal of Child Abuse \& Neglect, 12, 271-287.

[8] Izumi, U., Kazuko, S., Mariko, K., et al. (2014) A Perspective of Public Health Nurses on the Human Relations and Behavioral Characteristics of Fathers Who Abused Their Children. Japanese Journal of Public health Nursing, 2, 2-11.

[9] Yuri, M. (2008) Sexual Abuse to Children. Iwanamisyoten Press, Tokyo, 32-52.

[10] Kahn, R.L. \& Antonucci, T.C. (1980) Convoys over the Life Course: Attachment, Roles, and Social Support. In: Baltes, P.B. and Grim, O.G., Eds., Life Span Development and Behavior, Vol. 3, Academic Press, New York, 253-286.

[11] Japanese Nursing Association: Kanzya/Kazokunobougen/Bouryoku. http://www.nurse.or.jp/rinri/basis/boryoku/

[12] Masae, U., Kazuko, Y. and Yumiko, Y. (2006) Analysis of Support through Home Visits to Public Health Nurses in Child Abuse Prevention. Japanese Journal of Child Abuse and Neglect, 8, 280-289.

[13] Takeshi, T. (2008) Father of Children and Adolescents and Psychological Education and Support. Gendai No Espurit, 8, 126-136.

[14] Zisedaikenkyuusyo:kazokunikansurukokuseityousa.kekkontohuuhukankei,nihonnogenzyoutokadai. http://www2.ttcn.ne.jp/honkawa/9100.html

[15] Naikakuhukyouseisyakaiseisakutoukatukan: Syoushikataisakutaikou [kodomo/kosodateshiensakunogenzyoutokadai] to [kodomo/kosodateshiensakunogutaitekizissizyoukyou]. http://www8.cao.go.jp/shoushi/shoushika/law/taikou2.html

[16] Izumi, U. (2014) Details of the Psychosocial Characteristics of Fathers Who Have Abused Their Children as Seen by Public Health Nurses. Open Journal of Nursing, 4, 669-675. http://dx.doi.org/10.4236/ojn.2014.49071

[17] Japan Child and Family Research Institute (2009) Guidance for Child Abuse-3/31/2009 Welfare Labor Ministry Amendment Alert. Yuhikaku Press, Tokyo. 